\title{
SUBSTRATOS PARA CULTIVO DE FEIJOEIRO EM VASOS COM FERTIRRIGAÇÃO ( $\left.{ }^{1}\right)$
}

\author{
LEO HOFFMANN JUNIOR $\left({ }^{2}\right)$; NERINÉIA DALFOLLO RIBEIRO $\left({ }^{3} *\right)$; OSMAR SOUZA DOS SANTOS $\left({ }^{3}\right)$; \\ SANDRO LUIS PETTER DE MEDEIROS $\left({ }^{3}\right)$; EVANDRO JOST $\left({ }^{4}\right)$; NERISON LUIZ POERSCH $\left({ }^{4}\right)$
}

\begin{abstract}
RESUMO
Considerando a necessidade de se identificar um substrato apropriado para o cultivo de feijoeiro em vasos - objetivo deste trabalho - foram desenvolvidos dois experimentos em casa-de-vegetação, durante o ano de 2005, com a cultivar de feijoeiro TPS Nobre. Sete substratos foram avaliados: Plantimax ${ }^{\circ}$, casca de arroz carbonizada, vermiculita, areia, casca de arroz carbonizada $+20 \%$ de Plantimax ${ }^{\circledR}$, casca de arroz carbonizada $+20 \%$ de vermiculita e casca de arroz carbonizada $+20 \%$ de areia. O delineamento experimental utilizado foi inteiramente casualizado, com cinco repetições. Os nutrientes foram fornecidos semanalmente por fertirrigação e a água foi adicionada de maneira a ser reposto o volume consumido. Nos substratos avaliados constataram-se características químicas e físicas diferenciadas. Caracterizou-se o substrato comercial Plantmax ${ }^{\circledR}$ pela elevada capacidade de troca de cátions $\left(30,6 \mathrm{cmol} \mathrm{c} \mathrm{L}^{-1}\right)$ e maior capacidade de armazenamento de água por unidade de volume, o que contribuiu para a superioridade na produção de fitomassa seca das plantas e dos componentes do rendimento de grãos de feijão. O substrato comercial Plantmax ${ }^{\circledR}$ é apropriado para o cultivo de feijoeiro em vasos com o uso de fertirrigação.
\end{abstract}

Palavras-chave: Phaseolus vulgaris L., cultivo sem solo, solução nutritiva.

\section{ABSTRACT \\ SUBSTRATES FOR COMMON BEAN GROWN IN FLOWERPOTS WITH FERTIRRIGATION}

The objective of this paper was to identify an appropriate substrate for common bean grown in flowerpots. The experiments were carried out in a green house during 2005, with the TPS Nobre common bean cultivar. Seven substrates were evaluated: Plantimax ${ }^{\circledR}$, carbonized rice husks, vermiculite, sand, carbonized rice husks $+20 \%$ of Plantimax ${ }^{\circledR}$, carbonized rice husks $+20 \%$ of vermiculite and carbonized rice husks $+20 \%$ of sand. The experimental design was completely randomized with five replications. The nutrients were supplied weekly to fertigation and the water was added to refill the consumed volume. The evaluated substrates had different chemical and physical characteristics. The commercial substrate Plantmax ${ }^{\circledR}$ was characterized by high cations capacity exchange $\left(30.6 \mathrm{cmol} \mathrm{c} \mathrm{L}^{-1}\right)$ and the highest water storage capacity per volume unit, which contributed for the higher dry matter yield of the plants and for common bean grains yield components. Therefore, we concluded that commercial substrate Plantmax ${ }^{\circledR}$ is appropriate for the common bean cultivation in flowerpots with fertigation.

Key Words: Phaseolus vulgaris L., soilless cropping, nutrient solution.

$\left({ }^{1}\right)$ Recebido para a publicação em 16 de dezembro de 2005 e aceito em 6 de novembro de 2006.

$\left({ }^{2}\right)$ Aluno do Programa de Pós-graduação em Agronomia, Universidade Federal de Santa Maria (UFSM). Bolsista da CAPES.

$\left({ }^{3}\right)$ Departamento de Fitotecnia, Centro de Ciências Rurais, UFSM, 97105-900 Santa Maria (RS). E-mail: neiadr@smail.ufsm.br *Autora correspondente.

$\left({ }^{4}\right)$ Aluno do Curso de Agronomia da UFSM. Bolsista PIBIC/CNPq e BIC/FAPERGS, respectivamente. 


\section{Introdução}

São constatadas reduções da produtividade de grãos de feijão em função da ocorrência de elevada temperatura do ar - superior a $30 / 32{ }^{\circ} \mathrm{C}$ principalmente durante a sua fase reprodutiva (GONÇALVES et al., 1997; ANDRADE, 1998; MASSIGNAM et al., 1998), sendo o efeito negativo dependente do tempo em que a temperatura for superior a $30^{\circ} \mathrm{C}$, do valor máximo a ser atingido e do número de dias consecutivos em que essa situação for mantida (BARBANO et al., 2001).

A maioria dos trabalhos realizados para avaliar esses efeitos prejudiciais foi desenvolvida a campo, condição em que não se tem controle da intensidade e da duração da temperatura do ar limitante às plantas de feijoeiro. Assim, as câmaras de crescimento - fitotron - são estruturas mais apropriadas para a avaliação desses danos, embora com problemas de incidência de pragas e fitopatógenos limitantes ao crescimento e ao desenvolvimento das plantas. Por essa razão, os cultivos em substratos são mais indicados, devido às vantagens do manejo mais adequado da água, do fornecimento dos nutrientes em doses e épocas apropriadas e da redução de problemas fitossanitários (ANDRIOLO et al., 1999).

O conhecimento das características químicas e físicas é determinante na escolha do substrato mais adequado (Bellé e KäMPF, 1993) e, considerando-se que não há um universalmente válido para todas as espécies (ABAD, 1991), é interessante a avaliação do desempenho de plantas de feijoeiro nessa condição. Isso é justificado pelo fato de a maioria das informações ser referente às oleráceas, sendo inexistentes para essa leguminosa. Além disso, não é rotineira a exploração comercial dessa cultura em substrato em condições controladas, mas pode ser opção adequada em estudos científicos de melhoramento. Assim, o objetivo do trabalho foi identificar substratos adequados para o cultivo de feijoeiro em vasos com fertirrigação, em condições controladas de casa-de-vegetação.

\section{Material e Métodos}

Dois experimentos foram instalados em janeiro de 2005, em casa-de-vegetação do Departamento de Fitotecnia, da Universidade Federal de Santa Maria, Santa Maria (RS). No primeiro, foi considerado o período entre a semeadura e os 40 dias após a emergência e, no segundo, da semeadura até o fim do ciclo da cultura.
O delineamento experimental utilizado foi o inteiramente casualizado, com cinco repetições. Os tratamentos consistiram de sete substratos: Plantmax ${ }^{\circledR}$, casca de arroz carbonizada, vermiculita, areia, casca de arroz carbonizada $+20 \%$ de Plantimax ${ }^{\circledR}$, casca de arroz carbonizada $+20 \%$ de vermiculita e casca de arroz carbonizada $+20 \%$ de areia. A unidade experimental foi constituída por um vaso - com volume de 5 litros, contendo uma planta de feijoeiro da cultivar TPS Nobre.

As características físicas - densidade seca, volume de água retida e capacidade máxima de retenção de água - foram avaliadas nos substratos. A densidade seca foi determinada pela quantidade de matéria seca das amostras, utilizando-se método proposto por HOFFMANN (1970). O volume de água retida refere-se à umidade presente nas amostras em estado de saturação e a capacidade máxima de retenção de água é a expressão da quantidade de água em percentagem de massa úmida de substrato.

As características químicas determinadas foram: $\mathrm{pH}$ em água - em potenciômetro, como sugerido por HoffMANN (1970), e capacidade de troca de cátions (CTC), de acordo com metodologia descrita por TEDEsco et al. (1995).

Os nutrientes foram fornecidos em doses semanais, por fertirrigação, com a solução nutritiva proposta por HoAgLAND e ARNON (1950), porém, utilizando-se a metade da dose recomendada de nitrato. A água foi adicionada de maneira que o volume consumido seja reposto, sendo o excedente eliminado por drenagem natural.

Amostras da solução drenada foram coletadas semanalmente para a leitura da condutividade elétrica, irrigando-se abundantemente para lixiviação do excesso de sais do substrato, sempre que o valor da leitura fosse maior que $3,0 \mathrm{mS} . \mathrm{cm}^{-1}$, como recomendado por ANDRIOLO (2002).

Nas plantas avaliaram-se: números de dias da semeadura à emergência e desta à floração; fitomassas secas da raiz, parte aérea e total, no primeiro experimento e, alguns componentes do rendimento de grãos, no segundo experimento.

Os dados obtidos no primeiro (Tabela 2) e no segundo experimentos (Tabela 3) foram submetidos à análise da variância e as médias comparadas pelo teste de Tukey a $5 \%$ de probabilidade.

\section{Resultados e Discussão}

Nos substratos com casca de arroz carbonizada e na combinação de casca de arroz carbonizada $+20 \%$ de vermiculita, os valores de 
densidade foram inferiores ao considerado por GROLLI (1991) como satisfatório para a propagação de plantas (Tabela 1). Em material com baixa densidade pode ser acarretado problemas de fixação das plantas e tombamento no cultivo em vasos (Jansen et al., 1989 apud Schmitz et al., 2002). A maior densidade foi verificada na areia, o que pode ter afetado o crescimento das raízes. Nos demais substratos os valores de densidade foram adequados ao cultivo de plantas.

Com relação ao volume de água retida, os valores estavam na faixa ideal para cultivo em substratos (GroLLI, 1991). Já a capacidade máxima de retenção de água foi menor para a areia e maior para a casca de arroz carbonizada; a areia é mais densa e com menor capacidade de armazenamento de água por unidade de volume e de massa úmida.

Nos substratos avaliados constataram-se diferentes características químicas (Tabela 1). $\mathrm{O}$ pH dos substratos foi variável de 4,9 a 8,0 e, entre os materiais de base mineral - vermiculita e areia, apenas na areia o valor de $\mathrm{pH}$ estava na faixa ideal, de 6 a 7 (KÄMPF, 2000). Já para substratos com base orgânica, em nenhum deles o valor estava na faixa considerada satisfatória de pH - 5,2 a 5,5 (KäMPF, 2000).

Tabela 1. Características físicas e químicas dos substratos avaliados para cultivo de feijoeiro em vasos quanto à densidade (densidade), volume de água retida (volume), capacidade máxima de retenção de água em percentagem de massa úmida (CMR), pH em água (pH) e capacidade de troca de cátions (CTC). Santa Maria (RS), UFSM, 2005

\begin{tabular}{|c|c|c|c|c|c|}
\hline \multirow{2}{*}{ Substratos } & \multicolumn{3}{|c|}{ Características físicas } & \multicolumn{2}{|c|}{ Características químicas } \\
\hline & Densidade & Volume & CMR & $\mathrm{pH}(\mathrm{H} 2 \mathrm{O})$ & CTC \\
\hline $\mathrm{kg}$ & $\mathrm{m}^{-3}$ & $\mathrm{~m} 3 \mathrm{~m}^{-3}$ & $\%$ & \multicolumn{2}{|c|}{ cmolc L $^{-1}$} \\
\hline Plantmax $®$ & 418 & 0,41 & 49,4 & 4,9 & 30,6 \\
\hline Casca de arroz carbonizada (casca carb.) & 135 & 0,27 & 66,5 & 6,8 & 4,2 \\
\hline Vermiculita & 180 & 0,28 & 61,1 & 8,0 & 39,7 \\
\hline Areia & 1610 & 0,22 & 12,2 & 6,5 & 2,0 \\
\hline Casca carb. $+20 \%$ Plantmax ${ }^{\circledR}$ & 220 & 0,31 & 58,6 & 5,8 & 15,6 \\
\hline Casca carb. $+20 \%$ vermiculita & 149 & 0,28 & 65,1 & 6,4 & 17,1 \\
\hline Casca carb. $+20 \%$ areia & 494 & 0,33 & 39,7 & 6,6 & 4,8 \\
\hline \multirow[t]{2}{*}{ Ideal* } & $170-1000\left(^{1}\right)$ & $0,20-0,80\left(^{2}\right)$ & & $6,0-7,0\left(^{3}\right)$ & $>12\left({ }^{5}\right)$ \\
\hline & & & & $5,2-5,5\left(^{4}\right)$ & \\
\hline
\end{tabular}

* Valores considerados ideais de acordo com: $\left({ }^{1}\right)$ densidade, GROLLI $(1991) ;\left({ }^{2}\right)$ volume (Grolli, 1991); $\left({ }^{3}\right)$ pH, com materiais e mistura de base mineral (KÄMPF, 2000); $\left({ }^{4}\right)$ pH, com materiais e mistura de base orgânica (KÄMPF, 2000); $\left({ }^{5}\right)$ CTC (PENNINGSFELd, 1983).

Nos substratos Plantmax ${ }^{\circledR}$ e casca de arroz carbonizada $+20 \%$ de Plantmax ${ }^{\circledR}$, o pH foi inferior a 6, o que pode limitar sua utilização para o cultivo sem correção da acidez, pois a faixa de $\mathrm{pH}$ com mais disponibilidade de nutrientes é de 6 a 7 (Sснмiтz et al., 2002). Já com a utilização da vermiculita - pH 8,0, são necessários mais cuidados para se evitar a salinização, como os realizados conforme ANDRIOLO (2002).

A CTC é uma valiosa informação do potencial de fertilidade de um substrato, já que muitos cátions nele existentes são nutrientes (KIEHL, 1979; CARNEIRO, 1995). Assim, com os substratos casca de arroz carbonizada, areia e casca de arroz carbonizada + $20 \%$ de areia houve problemas no desenvolvimento e no crescimento das plantas de feijoeiro, devido aos valores de CTC menores do que os da faixa ideal $>12 \mathrm{cmol}_{\mathrm{c}} \mathrm{L}^{-1}$, estabelecida por PenNingsfeld (1983). Segundo essa especificação, nos demais substratos em que se obtiveram valores de CTC superiores ao mínimo ideal, não se têm problemas para o cultivo de plantas de feijoeiro em vasos.
Os números de dias da semeadura à emergência e desta à floração foram variáveis em função do substrato utilizado (Tabela 2). Observou-se maior precocidade para a emergência, na semeadura nos substratos Plantmax ${ }^{\circledR}$ e vermiculita, não estatisticamente distintos apenas da areia. Em trabalho com moringa (Moringa oleifera Lam.) obteve-se maior velocidade nesse processo no substrato Plantmax ${ }^{\circledR}$ do que em vermiculita (BEZERRA et al., 2004), sugerindo-se diferenças na emergência e na velocidade de germinação, em distintas espécies, quando cultivadas em determinado substrato.

Para o subperíodo emergência-floração, verificouse maior precocidade em plantas cultivadas em Plantmax ${ }^{\circledR}$ que só não foi distinto daquele em casca de arroz carbonizada $+20 \%$ de Plantmax ${ }^{\circledR}$. A duração desse subperíodo foi numérica, mas não estatisticamente maior para plantas cultivadas em areia (Tabela 2). Normalmente, plantas que florescem mais precocemente são de ciclo curto e, assim, mais sujeitas aos efeitos prejudiciais da elevada temperatura do ar durante o período reprodutivo, pois a floração ocorre em menor intervalo de dias, quando comparada à das cultivares de ciclos intermediário e longo. 
Tabela 2. Número de dias da semeadura à emergência (emergência), número de dias da emergência a floração (floração), fitomassa seca das raízes (raiz), da parte aérea (aérea) e total (total) de plantas de feijoeiro, cultivar TPS Nobre, cultivadas em diferentes substratos, em casa-de-vegetação. Santa Maria - RS, UFSM, 2005

\begin{tabular}{|c|c|c|c|c|c|}
\hline Substratos & Emergência & Floração & Raiz & Aérea & Total \\
\hline & \multicolumn{2}{|c|}{ dias } & & gramas & \\
\hline Plantmax® & $4,0 c^{*}$ & $32,4 \mathrm{c}$ & $5,04 a$ & $10,58 \mathrm{a}$ & $15,62 a$ \\
\hline Casca de arroz carbonizada (casca carb.) & $7,4 a$ & $38,6 \mathrm{ab}$ & $2,25 \mathrm{~b}$ & $2,66 \mathrm{~b}$ & $5,92 \mathrm{~b}$ \\
\hline Vermiculita & $4,0 \mathrm{c}$ & $37,8 \mathrm{ab}$ & $2,45 \mathrm{~b}$ & $5,37 \mathrm{~b}$ & $7,82 \mathrm{~b}$ \\
\hline Areia & $5,2 \mathrm{bc}$ & $39,4 a$ & $1,77 \mathrm{~b}$ & $3,72 \mathrm{~b}$ & $4,50 \mathrm{~b}$ \\
\hline Casca carb. $+20 \%$ Plantmax ${ }^{\circledR}$ & $6,2 \mathrm{ab}$ & $35,4 \mathrm{bc}$ & $2,27 \mathrm{~b}$ & $5,77 \mathrm{~b}$ & $8,05 \mathrm{~b}$ \\
\hline Casca carb. $+20 \%$ vermiculita & $6,2 \mathrm{ab}$ & $37,2 \mathrm{ab}$ & $1,64 \mathrm{~b}$ & $4,83 \mathrm{~b}$ & $6,47 b$ \\
\hline Casca carb. $+20 \%$ areia & $6,6 a b$ & $38,8 \mathrm{ab}$ & $1,86 \mathrm{~b}$ & $4,55 \mathrm{~b}$ & $6,41 \mathrm{~b}$ \\
\hline Média & 5,6 & $37,1 \mathrm{ab}$ & 2,47 & 5,49 & 7,97 \\
\hline C.V. $(\%)$ & 14,5 & 4,6 & 19,9 & 19,4 & 18,3 \\
\hline
\end{tabular}

*Médias ligadas pelas mesmas letras não são significativamente diferentes pelo teste de Tukey com $5 \%$ de probabilidade.

Com relação à produção de fitomassas secas de raízes, de parte aérea e total verificou-se superioridade de valores em Plantmax ${ }^{\circledR}$ (Tabela 2). Provavelmente, em função do valor mais elevado de CTC (Tabela 1) proporcionou-se mais capacidade de armazenamento e de fornecimento dos nutrientes às plantas e, mesmo com $\mathrm{pH}$ baixo, de 4,9, foram favorecidos o crescimento e o desenvolvimento das plantas. Além disso, nesse substrato se tem mais capacidade de armazenamento de água por unidade de volume, com contribuição de mais volume de água disponibilizada à planta durante o dia.

O substrato Plantmax ${ }^{\circledR}$ também foi um meio apropriado para o desenvolvimento de plantas de moringa (BEZERRA et al., 2004) e de limoeiro 'Cravo'(LiRA, 1990), além de mudas de maracujazeiro (LOPES, 1996), mas com menor desenvolvimento de plântulas de alface (MENEZES JúNIOR et al., 2000).

Nos componentes do rendimento de grãos foram constatados os maiores valores em plantas cultivadas em Plantmax ${ }^{\circledR}$ (Tabela 3 ). Nas misturas de substratos, os resultados não foram satisfatórios nessas variáveis analisadas (Tabela 2 e 3). Apesar das características físicas e químicas mais adequadas do Plantmax ${ }^{\circledR}$, na mistura desse com casca de arroz carbonizada, na proporção de $20 \%$, não foi acarretada melhoria significativa favorável aos componentes do rendimento.

Os resultados mais satisfatórios obtidos com o substrato comercial Plantmax ${ }^{\circledR}$ podem ser atribuídos ao maior volume de água retida e à maior capacidade de troca de cátions (Tabela 1), sendo favorecidos o crescimento das raízes (Tabela 2), a absorção de água e de nutrientes, o acúmulo de fitomassa e os componentes do rendimento de grãos de feijão (Tabela 3).
Tabela 3. Número de vagens (NVP), número de sementes (NSP) e massa de sementes (MSP) por planta de feijoeiro, cultivar TPS Nobre, cultivada em diferentes substratos, em casa-de-vegetação. Santa Maria (RS), UFSM, 2005

\begin{tabular}{lccc}
\hline Substratos & NVP & NSP & MSP** \\
\hline & & & gramas \\
Plantmax ${ }^{*}$ & $19,4 \mathrm{a}^{*}$ & $74,2 \mathrm{a}$ & $17,1 \mathrm{a}$ \\
Casca de arroz & $6,8 \mathrm{abcd}$ & $22,0 \mathrm{abc}$ & $4,1 \mathrm{abc}$ \\
carbonizada (casca carb.) & & & \\
Vermiculita & $13,0 \mathrm{abcd}$ & $43,0 \mathrm{abc}$ & $8,5 \mathrm{ab}$ \\
Areia & $9,2 \mathrm{abc}$ & $31,0 \mathrm{abc}$ & $6,0 \mathrm{abc}$ \\
Casca carb. $+20 \%$ & $5,8 \mathrm{abcd}$ & $24,0 \mathrm{abc}$ & $4,6 \mathrm{abc}$ \\
Plantmax ${ }^{\circledR}$ & & & \\
Casca carb. $+20 \%$ & $10,0 \mathrm{abc}$ & $34,8 \mathrm{abc}$ & $7,1 \mathrm{abc}$ \\
vermiculita & & & \\
Casca carb. $+20 \%$ & $8,6 \mathrm{abcd}$ & $28,2 \mathrm{abc}$ & $5,5 \mathrm{abc}$ \\
areia & & & \\
Média & 10,4 & 37,7 & 7,5 \\
C.V. (\%) & 15,9 & 20,9 & 25,9 \\
\hline
\end{tabular}

*Médias ligadas pelas mesmas letras não são significativamente diferentes pelo teste de Tukey com $5 \%$ de probabilidade.

** Dados ajustados a $13 \%$ de umidade.

\section{Conclusão}

O substrato comercial Plantmax ${ }^{\circledR}$ é apropriado para o cultivo de feijoeiro em vasos, em condições controladas de casa de vegetação, com fertirrigação.

\section{Agradecimentos}

Os autores agradecem à Fundação de Amparo à Pesquisa do Estado do Rio Grande do Sul pelo auxílio financeiro. 


\section{Referências}

ABAD, M. Los susbtratos hortícolas y técnicas de cultivo sin suelo. In: RALLO, L., NUEZ, F. (Eds). La horticultura Española em la C. E. Reus: Horticultura S.L, 1991.p. 271-280.

ANDRADE, M.J.B. Clima e solo. In: VIEIRA, C.; PAULA JÚNIOR, T.J.; BORÉM, A. Feijão: aspectos gerais e cultura no Estado de Minas. Viçosa: UFV, 1998. p.83-97.

ANDRIOLO, J.L. Olericultura geral: princípios e técnicas. Santa Maria: UFSM, 2002. 158 p.

ANDRIOLO, J.L.; DUARTE, T.S.; LUDKE, L.; SKREBSKY, E.C. Caracterização e avaliação de substratos para o cultivo do tomateiro fora do solo. Horticultura Brasileira, Brasília, v.17, n.3, p.215-219, 1999.

BARBANO, M.T.; BRUNINI, O.; WUTKE, E.B.; et al. Comparação entre valores observados e estimados de duração dos diferentes subperíodos de desenvolvimento da cultura do feijoeiro. Revista Brasileira de Agrometeorologia, Santa Maria, v.9, n.1, p.103-110, 2001.

BELLÉ, S.; KÄMPF, A.N. Produção de mudas de maracujáamarelo em substratos à base de turfa. Pesquisa Agropecuária Brasileira, Brasília, v.28, n.3, p.385-390, 1993.

BEZERRA, A.M.E.; MOMENTÉ,V.G.; MEDEIROS FILHO, S. Germinação de sementes e desenvolvimento de plântulas de moringa (Moringa oleifera Lam.) em função do peso da semente e do tipo de substrato. Horticultura Brasileira, Brasília, v.22, n.2, p.295-299, 2004.

CARNEIRO, J.G.A. Produção e controle de qualidade de mudas florestais. Curitiba: UFPR/FUPEF, 1995. 451 p.

GONÇALVES, S.L.; WREGE, M.S.; CARAMORI, P.H.; et al. Probabilidade de ocorrência de temperaturas superiores a $30^{\circ} \mathrm{C}$ no florescimento do feijoeiro (Phaseolus vulgaris L.), cultivado nas safras das águas no Estado do Paraná. Revista Brasileira de Agrometeorologia, Santa Maria, v.5, n.2, p.99107, 1997.

GROLLI, P.R. Composto de lixo domiciliar urbano como condicionador de substratos para plantas arbóreas. 1991. 125 f. Dissertação (Mestrado em Agronomia - Fitotecnia) Universidade Federal do Rio Grande do Sul, Porto Alegre.

HOAGLAND D. R.; ARNON D. L. The water culture methods for growing plants without soil. Berkeley: University of California, 1950. 32p. (Circular 347)

HOFFMANN, G. Verbindliche Metroden zur Untersuchung von TKS und Garterischen Erden. Mittelungen der VSLUFA, [s.1.], v.6, p.129-153, 1970.

KÄMPF, A.N. Seleção de materiais para uso como substrato. In: KÄMPF, A.N.; FERMINO, M.H. (Eds) Substrato para plantas: a base da produção vegetal em recipientes. Porto Alegre: Gênesis, 2000, p.139-145.
KIEHL, E.J. Manual de Edafologia: relações solo-planta. São Paulo: Editora Agronômica Ceres Ltda, 1979. 262 p.

LIRA, L.M. Efeito de substratos e do superfosfato simples no limoeiro (Citrus limonia Osbeck cv. Cravo) até a repicagem. 1990. 86 f. Dissertação (Mestrado em Fitotecnia) Universidade Federal de Lavras, Lavras.

LOPES, P.S.N. Propagação sexuada de maracujazeiro azedo (Plassiflora edulis Sims f. favicarpa Deg.) em tubetes: efeito da adubação nitrogenada e substratos. 1996. 52 f. Dissertação (Mestrado em Fitotecnia) - Universidade Federal de Lavras, Lavras.

MASSIGNAM, A.M.; VIEIRA, H.J.; FLESCH, R.D.; et al. Ecofisiologia do feijoeiro. II - Redução do rendimento pela ocorrência de altas temperaturas no florescimento. Revista Brasileira de Agrometeorologia, Santa Maria, v.6, n.1, p.41-45, 1998.

MENEZESJÚNIOR, F.O.G.; FERNANDES, H.S.; MAUCH, C.R.; SILVA, J.B. Caracterização de diferentes substratos e seu desempenho na produção de mudas de alface em ambiente protegido. Horticultura Brasileira, Brasília, v.18, n.3, p.164170, 2000.

PENNINGSFELD, F. Kultursubstrate fur den Gartenbau, Besonders in Deutschland; ein Kritischer \& Überblick. Plant and Soil, The Hague, v.75, p.269-281, 1983.

SCHMITZ, J.A.K.; SOUZA, P.V.D.; KÄMPF, A.N. Propriedades químicas e físicas de substratos de origem mineral e orgânica para o cultivo de mudas em recipientes. Ciência Rural, Santa Maria, v.32, n.6, p.937-944, 2002.

TEDESCO, M.J.; GIANELLO, C.; BISSANI, C.A.; BOHNEN, H.; WOLKWEISS, S.J. Análises de solos, plantas e outros materiais. 2 ed. Porto Alegre: UFGRS / Departamento de Solos, 1995. 174 p. (Boletim Técnico, 5) 